\title{
Changes in left ventricular diastolic filling during the development of left ventricular hypertrophy: Observations using Doppler echocardiography in
}

\author{
a unique canine model
}

To examine changes in diastolic left ventricular filling during the development of left ventricular hypertrophy, serial pulsed Doppler echocardiographic studies were performed in a canine model of left ventricular hypertrophy Induced by neurogenic pressor eplsodes. This model is unique since left ventricular hypertrophy develops without sustained hypertension. The neurogenic pressor episodes produced progressive increases in left ventricular mass of $17 \%$ by 3 weeks $(p<0.03)$ and of $23 \%$ by 9 weeks $(p<0.001)$. During the course of hypertrophy development, there were no changes in resting heart rate, blood pressure, left ventricular volumes or ejection fraction, or end-systolic wall stress. However, peak early filling (peak E) velocity decreased from $65 \pm 5 \mathrm{~cm} / \mathrm{sec}$ to $53 \pm 4 \mathrm{~cm} / \mathrm{sec}$ by 3 weeks $(p<0.05)$ and remained depressed at 9 weeks. In addition, peak E/A (the ratio of early to late peak filling) decreased by 3 weeks $(p<0.01)$ and the contribution of atrial filling to total left ventricular diastolic filling increased by 9 weeks $(p<0.005)$. There were significant correlations between the changes in left ventricular mass and the change in peak $E$ velocity at 3 weeks $(r=-0.92, p<0.001)$ but not at 9 weeks. These data indicate that left ventricular filling abnormalities occur early in the course of the development of left ventricular hypertrophy, are not a result of loading alterations related to sustained hypertension, and do not change significantly following increasing stages of hypertrophy. (Am HEART J 1991;121:1759.)

Andrew J. Buda, MD, Ying Li, MD, David Brant, MS, Lisa C. Krause, MS, and Stevo Julius, MD, $\mathrm{ScD}$. Ann Arbor, Mich.

Left ventricular hypertrophy is known to alter passive pressure-volume characteristics and reduce compliance. ${ }^{1}$ These changes ultimately should affect left ventricular diastolic filling, but few studies have specifically examined this issue during the development of left ventricular hypertrophy. In this regard, Doppler echocardiography has provided a relatively simple method to examine alterations in left ventricular filling dynamics that may occur in the course of developing hypertrophy. With the use of Doppler echocardiography, a number of studies have examined left ventricular filling characteristics in patients

From the Divisions of Cardiology and Hypertension, Department of Internal Medicine, University of Michigan Medical Center.

This work was supported in part by grants RO1 HL 34844 from the National Institutes of Health, National Heart, Lung, and Blood Institute, Bethesda, Md.

Received for publication Oct. 9, 1990; accepted Nov. 23, 1990.

Reprint requests: Andrew J. Buda, MD, Cardiology Division, University of Michigan Medical Center, 1500 E. Medical Center Dr, TC-3910, Ann Arbor, MI 48109-0366

$4 / 1 / 28431$ with hypertension, with and without concomitant left ventricular hypertrophy, ${ }^{2-6}$ and abnormalities in diastolic left ventricular filling have been observed in the absence of systolic dysfunction. However, the time course of left ventricular filling abnormalities in hypertrophic disease remains uncertain. Several investigators ${ }^{2,4}$ have argued that changes in left ventricular diastolic filling occur early in the hypertrophic process, since patients with mild hypertension but without left ventricular hypertrophy have abnormalities of diastolic filling. Moreover, others ${ }^{7,8}$ have suggested that these diastolic filling abnormalities are relatively fixed since often they fail to normalize despite regression of hypertrophy in patients during antihypertensive therapy. However, these studies examining diastolic filling are fundamentally limited, since loading conditions are also altered in the hypertensive hypertrophic patient. Since these loading alterations may affect left ventricular filling independent of the hypertrophic process, ${ }^{9}$ the effect of left ventricular hypertrophy without concomitant loading has not been thoroughly examined. 
Recently, we ${ }^{10}$ developed a canine model of left ventricular hypertrophy using neurogenic pressor episodes. This model is unique since left ventricular hypertrophy develops without sustained hypertension. As a result, this model provided us the opportunity to examine serial changes in left ventricular diastolic filling using Doppler echocardiography during the development of left ventricular hypertrophy without the confounding changes produced by loading alterations. Our observations indicate that diastolic filling abnormalities occur early following the development of left ventricular hypertrophy and do not change significantly following increasing stages of hypertrophy.

\section{METHODS}

Our experimental procedures complied with guidelines of the University of Michigan Committee on the Use and Care of Animals. The University of Michigan is accredited by the American Association of Accreditation of Laboratory Animal Care and animal care and use conforms to the standards in The Guide for the Care and Use of Laboratory Animals, Department of Health, Education, and Welfare, Publication No. NIH 78-23, revised 1978.

Experimental model. The experimental model that we used has recently been reported in detail. ${ }^{10}$ In brief, eight adult mongrel dogs were instrumented with a subcutaneous port (VAP Norfolk Medical Products, Inc., Skokie, Ill.) connected to the infrarenal abdominal aorta for monitoring of intraarterial blood pressure. The pressures were measured with a Hewlett-Packard $1290 \mathrm{C}$ strain gauge manometer (Hewlett-Packard Co., Medical Products Group, Andover, Mass.) connected to an $8805 \mathrm{D}$ signal conditioner, stored on magnetic tape, and later analyzed by a signal analysis data acquisition system sampling the arterial pulse wave form at 250 samples per second ( $\mathrm{Po}-\mathrm{Ne}-\mathrm{Nah}$, Inc., Storrs, Conn.). The acquisition system archived systolic pressure, diastolic pressure, mean pressure, and heart rate averages for every minute. These 1 -minute values were then averaged every 10 minutes to obtain an average period value.

The animals were then trained for 3 weeks to rest in a sling and for another week to adjust to the compression suit (Jobst Institute, Toledo, Ohio). The suit encompassed the hind limb and the gluteal region, but spared the abdomen. The eight trained animals were then brought to the laboratory every day to undergo $30 \mathrm{~mm} \mathrm{Hg}$ suit compression for a 3-hour schedule in the morning and another 3 hours in the afternoon. The daily 6 -hour compression schedules were maintained over 9 weeks. The average increase of the mean arterial pressure during these compression episodes was 21 $\mathrm{mm} \mathrm{Hg}$ for the first 3 weeks, $23 \mathrm{~mm} \mathrm{Hg}$ for the second 3 -week period, and $21 \mathrm{~mm} \mathrm{Hg}$ for the last 3-week interval. Throughout this time, the blood pressure consistently fell to the baseline value immediately after decompression. ${ }^{10}$

Echocardiographic and Doppler studies. Two-dimen- sional echocardiographic and Doppler examinations (Model MK600, Advanced Technology Laboratories, Bellevue, Wash.) were performed before the initiation of the compression, and at the end of the third and ninth week of compression. In all instances, the examinations were performed in the basal state without the inflation of the compression suit. The animals were studied on their right side on an examination table that had a section removed to provide a window for transducer placement. The transducer was positioned from below, at the point of maximal cardiac impulse. Short-axis images were obtained at the mid-papillary muscle and mitral valve levels of the left ventricle. Long-axis images were obtained with the transducer rotated until the longest length was visualized. Pulsed Doppler examination of the left ventricular inflow was performed with a $3.0 \mathrm{MHz}$ transducer. With the use of the apical four-chamber view, the Doppler sample volume ( $3 \mathrm{~mm}$ size) was placed in the mitral valve funnel just on the left ventricular side of the mitral anulus. The sample volume position was then adjusted so as to position the ultrasound beam as parallel to left ventricular inflow as possible. The peak velocities during rapid ventricular filling and during atrial contraction were recorded for at least five cardiac cycles at a paper speed of 50 or $100 \mathrm{~mm} / \mathrm{sec}$ for further analysis.

Two-dimensional echocardiographic analysis was performed with the use of a Diasonics microcomputer-based digitizing system (Diasonics Inc., Milpitas, Calif.) that has been previously validated in our laboratory..$^{11}$ End-diastolic frames were selected for analysis with the use of the $\mathrm{R}$ wave in lead 2 as a marker of end diastole. Endocardial and epicardial borders of the cross-sectional view at the midpapillary and mitral valve levels were carefully traced directly from the video display onto a digitizing tablet for three consecutive beats during normal sinus rhythm. Left ventricular length was determined by a measurement of the length from apex to the mitral valve using a long-axis view. Volumes were determined by Simpson's rule and mass was calculated by subtracting epicardial volumes from endocardial volumes and multiplying the result by the specific gravity of myocardial muscle. ${ }^{12}$ The accuracy of our echocardiographic measurement of left ventricular mass was previously reported in this animal model by anatomic validation. ${ }^{10}$ In that study, postmortem left ventricular weight correlated extremely well with echocardiographic mass obtained just before putting the animals to death $(r=0.93, \mathrm{y}=21.2+1.2 \mathrm{x})$. The average wall thickness was obtained as the mean end-diastolic wall thickness over 22.5-degree radial intervals in the midpapillary short-axis view. The relative wall thickness was calculated as: average wall thickness/left ventricular end-diastolic dimension. An index of end-systolic meridional wall stress was calculated by the formula: (0.334 P $\times$ LVID/PWT [1+PWT/LVID]), where $\mathrm{P}=$ systolic blood pressure, $\mathrm{PWT}=$ posterior wall thickness, and LVID = left ventricular internal diameter. ${ }^{13}$ The blood pressures used were resting blood pressures obtained prior to compression via the chronically instrumented subcutaneous port connected to the infrarenal ab- 


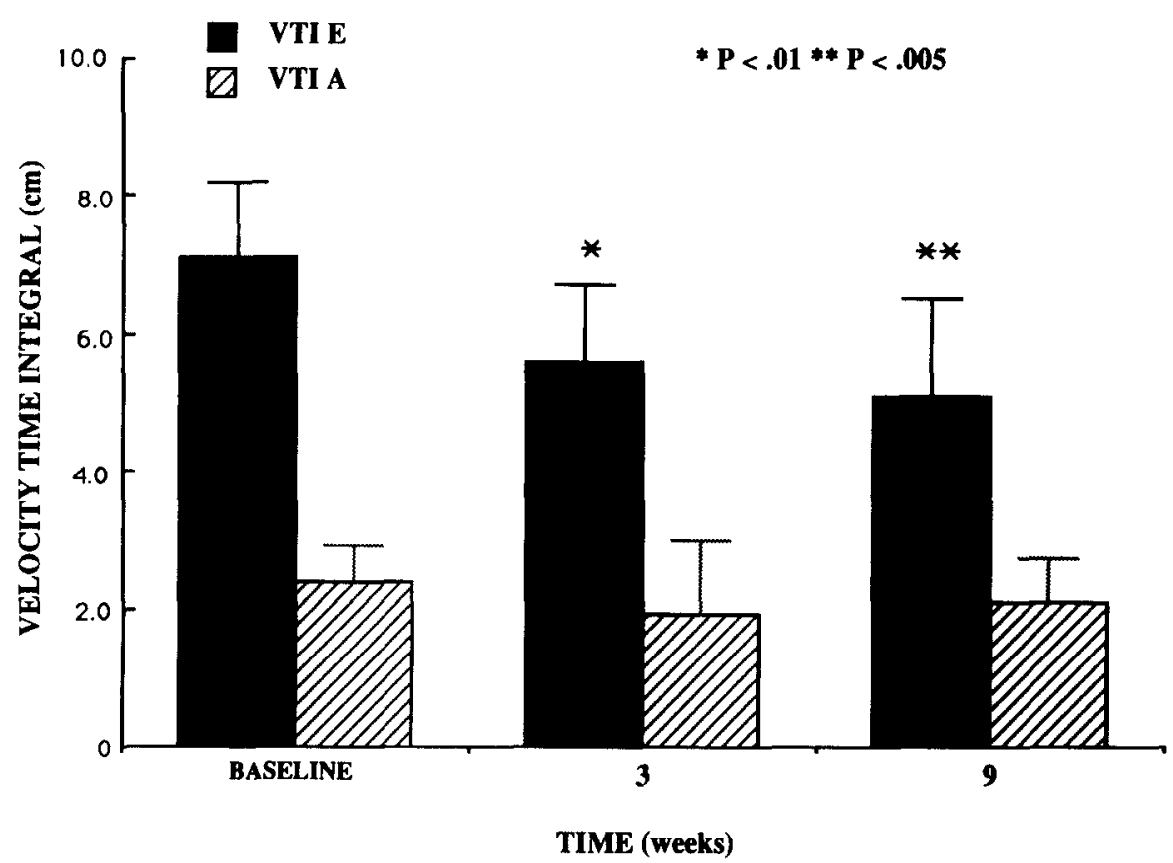

Fig. 1. The velocity-time integrals for the early diastolic filling period (VTIE) and the atrial diastolic filling period (VTI A) at baseline, at 3 weeks, and at 9 weeks.

dominal aorta. A blood pressure measurement was made by inserting a needle into the port using stcrile techniques.

All Doppler measurements were made using a computer interfaced digitizing tablet and Doppler analysis program (Freeland Medical Systems, Indianapolis, Ind.). The average of at least three consecutive cardiac cycles was taken and Doppler waveforms were traced through the modal velocities. The peak early diastolic velocity (peak E) and peak velocity during atrial contraction (peak A) were measured. The velocity-time integral for the early diastolic filling period (VTI E) and the atrial diastolic filling period (VTI A) were derived by digitizing the contour of the darkest portion of the curve (Fig. 1). Also, the ratio of the early to late peak filling (peak E/A) and velocity-time integrals (VTI E/A) were derived. When atrial contraction occurred before the mitral deceleration slope had decreased to the zero baseline, the slope was linearly extrapolated to the baseline for measurement of the velocity time integral. In addition, the following Doppler parameters were calculated: the total velocity-time integral (VTI total); the ratio of VTI A to VTI total (which represents the relative contribution of atrial contraction to total filling); and the ratio of VTI E to VTI total (which represents the contribution of early filling to total filling). The following parameters of diastolic function were also calculated by means of the mitral inflow Doppler velocities: (1) Peak filling rate (in milliliters per second) was determined as the product of the peak early diastolic velocity and the crosssectional area of the mitral anulus. (2) Normalized peak filling rate (measured in $\mathrm{sec}^{-1}$ ) was determined as peak filling rate divided by the left ventricular end-diastolic volume. (3) Atrial filling rate was determined as the product of the peak atrial velocity and the cross-sectional area of the mitral anulus.

The beat-to-beat variation coefficients for selected Doppler diastolic measurements have been reported previously from our institution ${ }^{14}$ : total velocity-time integral, $2.4 \%$; late diastolic velocity-time integral, $3.8 \%$; and peak late velocity, $4.2 \%$. Also, the interobserver variability for selected Doppler measurements has been reported: total velocity-time integral, $2.8 \%$; late diastolic velocity-time integral, $3.8 \%$; peak late diastolic velocity, $2.1 \%$.

Statistical analysis. All data are reported as mean \pm standard error. One-way analysis of variance was used to examine changes over time applying Bonferroni's correction to determine significant differences for repeated measures. Linear regression was used to determine correlations between left ventricular structural indexes and Doppler filling parameters. The probability $(p)$ was considered to be statistically significant when $p$ was less than 0.05 .

\section{RESULTS}

There were no changes in baseline heart rate or systolic and diastolic blood pressure at 3 weeks or 9 weeks of study (Table I). The left ventricular structural and functional indexes are summarized in $\mathrm{Ta}$ ble II. By 3 weeks, left ventricular mass had increased by $17 \%(p<0.03)$ and by 9 weeks it had increased by $23 \%(p<0.001)$. The average wall thickness increased by $1 \mathrm{~mm}$ at 3 weeks $(p<0.05)$ and by $1.5 \mathrm{~mm}$ 
Table I. Hemodynamic measurements

\begin{tabular}{cccc}
\hline & Baseline & Week 3 & Week 9 \\
\hline $\begin{array}{c}\text { Heart rate } \\
\text { (beats } / \mathrm{min})\end{array}$ & $90 \pm 6$ & $95 \pm 5$ & $90 \pm 6$ \\
MAP (mm Hg) & $119 \pm 3$ & $122 \pm 6$ & $123 \pm 8$ \\
\hline
\end{tabular}

MAP, Mcan artcrial pressure.

Table II. Left ventricular structure and function

\begin{tabular}{lccc}
\hline & Baseline & Week 3 & Week 9 \\
\hline LV mass (gm) & $78 \pm 9$ & $91 \pm 7^{*}$ & $96 \pm 7 \dagger$ \\
AVF wall thickne.ss & $0.9 \pm 0.8$ & $1.0 \pm 0.7^{*}$ & $1.1 \pm 0.8^{*}$ \\
$\quad(\mathrm{~cm})$ & & & \\
REL wall thickness & $0.51 \pm 0.04$ & $0.57 \pm 0.05$ & $0.60 \pm 0.04$ \\
$\quad(\mathrm{~cm})$ & & & \\
LVEDV $\left(\mathrm{cm}^{3}\right)$ & $44 \pm 3$ & $46 \pm 4$ & $48 \pm 4$ \\
LVESV $\left(\mathrm{cm}^{3}\right)$ & $13 \pm 1$ & $13 \pm 1$ & $14 \pm 1$ \\
LVEF $(\%)$ & $70 \pm 2$ & $72 \pm 1$ & $72 \pm 2$ \\
End-systolic & $186 \pm 13$ & $184 \pm 14$ & $176 \pm 12$ \\
$\quad$ LV wall stress & & & \\
$\quad($ dynes/cm & & & \\
\hline
\end{tabular}

$\Lambda V E, \Lambda$ verage; LV, left ventricular; LVEDV, left ventricular end-diastolic volume; LVEF, left ventricular ejection fraction; LVESV, left ventricular end-systolic volume; REL, relative.

${ }^{*} p<0.05$ versus baseline.

t $p<0.001$ versus baseline

at 9 weeks $(p<0.05)$. There was a trend toward an increase in relative left ventricular wall thickness, but this increase did not quite reach statistical significance $(p=0.07)$. Both left ventricular end-diastolic and end-systolic volumes did not change over the study interval. The left ventricular ejection fraction was $70 \pm 2 \%$ at baseline and did not change over the 9 weeks of study. Peak systolic wall stress was $186 \pm 13$ dynes $/ \mathrm{cm}^{3}$ at baseline and tended to decrease over the 9 weeks, but this decrease did not reach statistical significance.

The peak mitral flow velocities are summarized in Table III. The peak $\mathrm{E}$ velocity decreased significantly from $65 \pm 5 \mathrm{~cm} / \mathrm{sec}$ at baseline to $53 \pm 4 \mathrm{~cm} / \mathrm{sec}$ at 3 weeks $(p<0.02)$. There was no further change in peak $\mathrm{E}$ velocity at 9 weeks. Peak A velocity was $37 \pm 2 \mathrm{~cm} / \mathrm{sec}$ at baseline and decreased slightly by 9 weeks to $32 \pm 2 \mathrm{~cm} / \mathrm{sec}(p<0.05)$. A a result of the significant decrease in peak $\mathrm{E}$ velocity, the peak $\mathrm{E} / \mathrm{A}$ ratio decreased significantly, from $1.70 \pm 0.10$ at baseline to $1.60 \pm 0.09$ at 3 weeks $(p<0.01)$, and decreased further to $1.53 \pm 0.04(p<0.05)$ at 9 weeks. As illustrated in Fig. 2, the decrease in peak E/A ratio paralleled the increase in left ventricular mass over the 9 weeks of study.
Table III. Peak mitral valve flow velocities

\begin{tabular}{lccc}
\hline & Baseline & Week 3 & Week 9 \\
\hline $\begin{array}{c}\text { Peak E } \\
(\mathrm{cm} / \mathrm{sec})\end{array}$ & $65 \pm 5$ & $53 \pm 4^{*}$ & $49 \pm 4 \ddagger$ \\
$\begin{array}{c}\text { Peak A } \\
(\mathrm{cm} / \mathrm{sec})\end{array}$ & $37 \pm 2$ & $34 \pm 2$ & $32 \pm 2^{*}$ \\
Peak E/A ratio & $1.70 \pm 0.10$ & $1.60 \pm 0.09 \dagger$ & $1.53 \pm 0.04^{*}$ \\
\hline
\end{tabular}

Peak E, Peak early filling velocity; Peak A, peak late filling velocity.

${ }^{*} p<0.05$ versus baseline.

$\dagger_{p}<0.01$ versus baseline.

$\ddagger p<0.005$ versus baseline.

There were also similar changes in velocity-time integrals, as outlined in Table IV and Fig. 1. The total diastolic velocity-time integral decreased significantly at 3 weeks, from $9.4 \pm 0.7 \mathrm{~cm}$ to $8.1 \pm 0.4 \mathrm{~cm}$, but did not reach statistical significance. By 9 weeks, total diastolic velocity-time integral decreased to $7.4 \pm 0.7 \mathrm{~cm}(p<0.03)$. The $\mathrm{E}$ wave velocity-time integral decreased markedly from $7.1 \pm 0.4 \mathrm{~cm}$ to $5.6 \pm 0.4 \mathrm{~cm}$ at 3 weeks $(p<0.01)$ and remained markedly reduced at 9 weeks $(5.1 \pm 0.5 \mathrm{~cm}$, $p<0.003$ ). The A wave velocity-time integral decreased slightly but did not change significantly throughout the 9 weeks of study. Furthermore, the contribution of early to total left ventricular filling did not change throughout the study. However, as a result of the decrease in early filling velocities, the contribution of atrial filling to total left ventricular diastolic filling increased significantly by 9 weeks of study $(p<0.02)$, and the velocity-time integral E/A ratio decreased by 9 weeks $(p<0.003)$.

The changes in left ventricular filling rates are summarized in Table $V$. Peak filling rate decreased $28 \%(p<0.05)$ at 3 weeks and decreased further at 9 weeks $(p<0.01)$. Similarly, normalized filling rate and atrial filling rate significantly decreased at 3 weeks and remained depressed at 9 weeks.

In an effort to determine potential correlations between filling velocities and left ventricular structural changes, linear regression analyses were made between Doppler variables and left ventricular wall thickness. Significant correlations were found between left ventricular mass and peak $E$ velocity at 3 weeks $(r=-0.92, p<0.001)$ (Fig. 3 ). This correlation was not apparent at 9 weeks of study. Peak E/A velocity correlated with left ventricular mass at 3 weeks $(r=-0.57, p<0.05)$ but not at 9 weeks. There was also a significant correlation between left ventricular average wall thickness and peak $E$ velocity at 3 weeks $(r=-0.87, p<0.01)$ (Fig. 4) but not at 9 weeks 

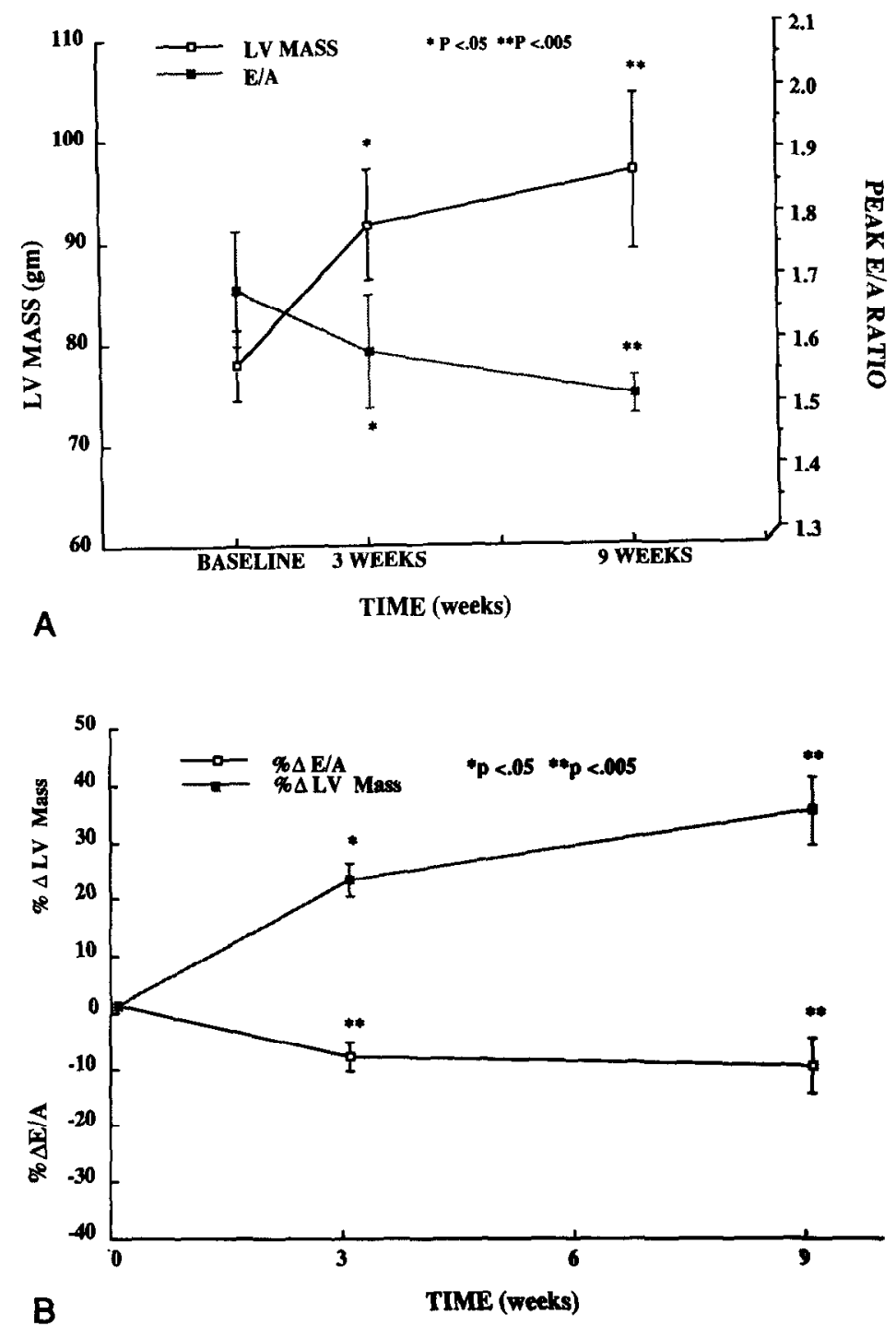

Fig. 2. A, The ratio of the early to late peak filling (PEAK E/A) and left ventricular mass (LVMASS at baseline, at 3 weeks, and at 9 weeks. B, The percent change in peak E/A and left ventricular mass ( $L V$ $M A S S$ ) over the 9-week study. Note that the decrease in peak E/A parallels the increase in left ventricular mass.

$(r=-0.66, p=0.08)$. However, there was no significant correlation between left ventricular mass and peak $A$ or peak E/A at 3 or 9 weeks of study.

\section{DISCUSSION}

Our experimental model of left ventricular hypertrophy induced by repeated neurogenic pressor episodes of hindquarter compression has recently been reported to produce an approximate $30 \%$ increase in left ventricular mass, ${ }^{10}$ which is comparable to that of other experimental models of left ventricular hypertrophy produced by renal artery clamp or by per- inephritic hypertension. ${ }^{15-17}$ This degree of hypertrophy is also similar to that encountered in patients with chronic hypertension. ${ }^{18}$ The neurogenic model of left ventricular hypertrophy produces progressive and significant increases in left ventricular mass of approximately $15 \%$ by 3 weeks, and $30 \%$ by 9 weeks. ${ }^{10}$ This neurogenic model is unique in that hypertrophy occurs despite a lack of sustained hypertension and may be in part related to sympathetic stimulation, as evidenced by increased norepinephrine responses to the compressions. ${ }^{10}$

This unique experimental model has allowed us 


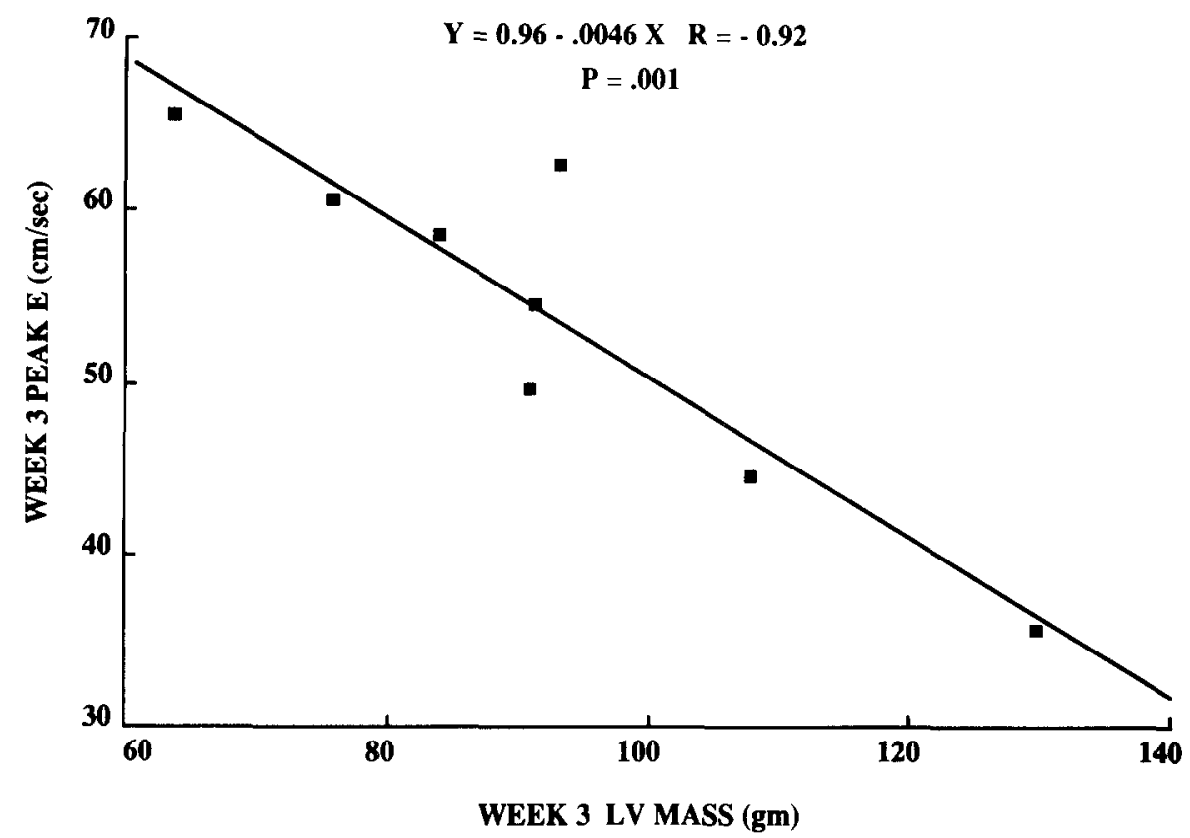

Fig. 3. The correlation between the peak early diastolic velocity (PEAK E) and the left ventricular mass (LVMASS) at 3 weeks.

Table IV. Left ventricular diastolic velocity-time integrals

\begin{tabular}{lccc}
\hline & Baseline & Week 3 & Week 9 \\
\hline Total VTI (cm) & $9.4 \pm 0.7$ & $8.1 \pm 0.4$ & $7.4 \pm 0.7^{*}$ \\
VTI E (cm) & $7.1 \pm 0.4$ & $5.6 \pm 0.4 \dagger$ & $5.1 \pm 0.5 \ddagger$ \\
VTI A (cm) & $2.4 \pm 0.2$ & $1.9 \pm 0.4$ & $2.1 \pm 0.2$ \\
VTI E/TOT & $0.75 \pm 0.01$ & $0.72 \pm 0.02$ & $0.69 \pm 0.01^{*}$ \\
VTI A/TOT & $0.26 \pm 0.02$ & $0.28 \pm 0.03$ & $0.31 \pm 0.02^{*}$ \\
VTI E/A & $2.9 \pm 0.2$ & $2.8 \pm 0.3$ & $2.3 \pm 0.1 \ddagger$ \\
\hline
\end{tabular}

Total VTI, Total velocity-time integral; VTI $\mathbf{E}$, velocity-time integral for early diastolic filling period; VTI A, velocity-time integral for atrial diastolic filling period; VTI E/TOT, contribution of early filling to total filling; VTI A/TOT, relative contribution of atrial contraction to total filling; VTI E/A, ratio of early to late peak filling velocity-time integrals.

${ }^{*} p<0.05$ versus baseline.

$\uparrow p<0.01$ versus baseline.

$\ddagger p<0.005$ versus baseline

the opportunity to investigate changes in left ventricular filling, measured by Doppler echocardiography during the course of left ventricular hypertrophy development, without the confounding effect of sustained hypertension. We observed changes in left ventricular filling with left ventricular hypertrophy evidenced by a decrease in peak early diastolic filling, a reduction in the early diastolic velocity-time integral, and a decreased rate of early diastolic deceleration. Similar changes have been noted in hy-
Table V. Left ventricular filling rates

\begin{tabular}{lccc}
\hline & Baseline & Week 3 & Week 9 \\
\hline $\begin{array}{c}\text { Peak filling rate } \\
\quad(\mathrm{ml} / \mathrm{sec})\end{array}$ & $195 \pm 15$ & $163 \pm 5^{*}$ & $151 \pm 9^{\dagger}$ \\
$\begin{array}{c}\text { Normalized filling } \\
\text { rate }\left(\mathrm{sec}^{-1}\right)\end{array}$ & $4.7 \pm 0.5$ & $3.8 \pm 1.3$ & $3.3 \pm 0.5^{*}$ \\
$\begin{array}{c}\text { Atrial filling rate } \\
(\mathrm{ml} / \mathrm{sec})\end{array}$ & $221 \pm 2$ & $181 \pm 4$ & $166 \pm 6$ \\
\hline
\end{tabular}

${ }^{*} p<0.05$ versus baseline.

$+p<0.01$ versus baseline.

pertensive patients with and without left ventricular hypertrophy. ${ }^{2-6}$ Importantly, we noted that these abnormalities of diastolic left ventricular filling occurred early (by 3 weeks) in the course of left ventricular hypertrophy when left ventricular mass had increased by only $17 \%$. These filling changes cannot be explained by changes in heart rate or loading conditions, which did not alter over this period of time. There were no further significant changes in left ventricular diastolic filling during the subsequent 6 weeks of left ventricular hypertrophy progession, during which left ventricular mass increased by an additional $6 \%$. It is also interesting to note that these changes in filling correlated with increases in left ventricular mass during the initial 3 weeks but that 


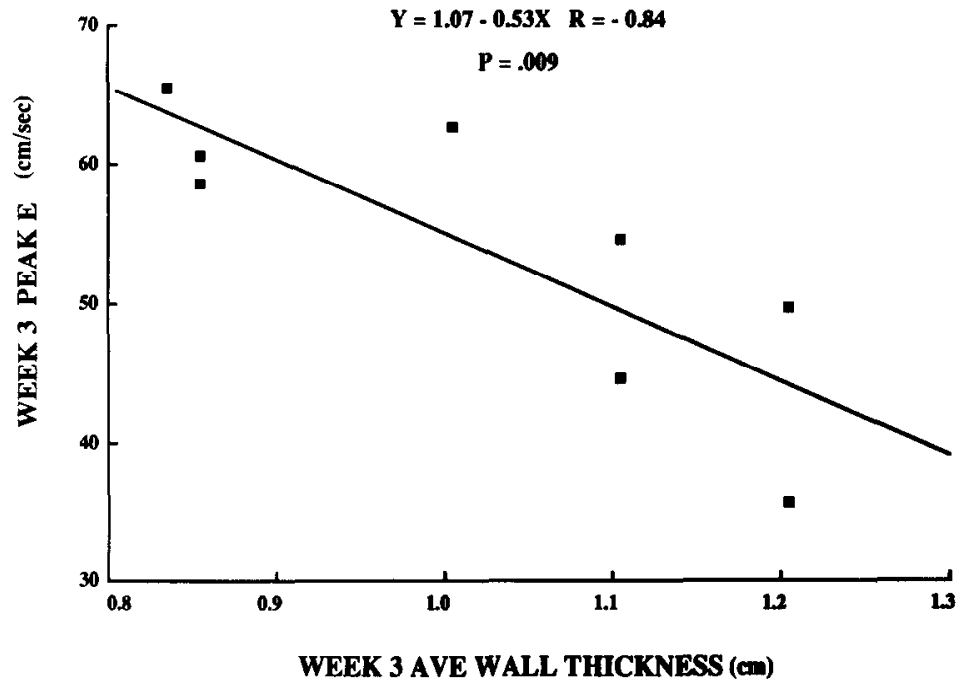

Fig. 4. The correlation between the peak early diastolic velocity (PEAK E) and the left ventricular average $(A V E)$ wall thickness at 3 weeks.

these correlations were not apparent by 9 weeks. These data indicate that diastolic left ventricular filling abnormalities are an early manifestation of left ventricular hypertrophy and occur at a time point prior to the development of marked hypertrophy. This may help to explain the clinical observation that diastolic filling abnormalities occur in hypertensive patients who have little or no detected left ventricular hypertrophy. ${ }^{2,3,7,19}$

A number of clinical studies in hypertensive patients using Doppler echocardiography ${ }^{2-7}$ or radionuclide angiographic techniques ${ }^{19-21}$ have documented abnormalities of left ventricular filling before alterations in systolic left ventricular performance. However, there are few data related to changes in left ventricular filling with changes in left ventricular mass. There is only one other report that has specifically examined left ventricular diastolic filling during progressive left ventricular hypertrophy. In that recent study, Douglas et al. ${ }^{17}$ used a canine model of perinephritic hypertension that produced a $28 \%$ increase in left ventricular mass, similar to the degree of hypertrophy that we observed. They examined diastolic left ventricular inflow and wall thinning variables before and $2,4,8$, and 12 weeks after the creation of hypertension. In accord with our results, they noted diastolic filling abnormalities as early as 2 weeks following hypertension, with impairment of the peak rate of wall thinning. By 4 weeks, they observed a decrease in peak $\mathrm{E} / \mathrm{A}$ and an increased dependence on atrial systolic filling. However, there were no significant changes noted in peak $E$, peak $A$, or atrial filling fraction. In addition, they found weak but significant correlations between left ventricular mass and late velocity flow and atrial filling fraction.

Although our results generally agree with and confirm those of Douglas et al.,17 there are specific differences between our studies that deserve comment. Unlike Douglas et al., ${ }^{17}$ we noted a decrease in peak early diastolic filling and a reduction in the early diastolic velocity-time integral during the development of hypertrophy. Moreover, we found correlations between left ventricular hypertrophy and diastolic filling at 3 weeks but not at 9 weeks. These apparent differences between our results and those of Douglas et al ${ }^{17}$ may largely by explained by the differences of the hypertrophy models used. The perinephritic model of Douglas et al. ${ }^{17}$ resulted in a sustained increase in systolic blood pressure, whereas our neurogenic model had normal systolic blood pressure during the Doppler studies. Since loading conditions may influence left ventricular filling patterns independent of other factors, ${ }^{9,}{ }^{22-24}$ this specific difference in the hypertrophic models may explain the minor differences in diastolic filling observed in the two studies.

In a clinical study, Szlachcic et al. ${ }^{7}$ examined hypertensive patients treated with diltiazem and found no change in left ventricular filling abnormality despite a $10 \%$ regression of left ventricular mass. This finding agrees with the findings of other similar studies. ${ }^{3,7,8}$ In view of our data, which demonstrate 
that left ventricular filling remains abnormal despite minimal hypertrophy, it is possible that further regression of hypertrophy is necessary to demonstrate normalization of left ventricular filling.

There are a number of mechanisms that may alter left ventricular filling in left ventricular hypertrophy. ${ }^{1}$ These include increased chamber stiffness and alterations of left ventricular relaxation. Detailed analysis of stress-strain relations has suggested that reduced chamber compliance is related to ventricular mass and in part to increased collagen content. ${ }^{25-27}$ Although we did not specifically measure chamber stiffness or compliance directly, the echocardiographically determined left ventricular radius-to-thickness ratio, an important determinant of left ventricular compliance, ${ }^{25,28}$ tended to increase, suggesting a decrease in left ventricular compliance. In addition, the significant relationship that was found between alterations in left ventricular filling and increases in left ventricular mass further supports the fact that increased chamber stiffness is an important mechanism in alterations in diastolic function in left ventricular hypertrophy. Several other investigators ${ }^{29-31}$ have also observed a significant relationship between left ventricular filling and left ventricular mass in hypertensive patients, further supporting this hypothesis. In addition to alterations in left ventricular mass, experimental studies have demonstrated that the sarcoplasmic reticulum's uptake of calcium may be reduced in myocardial hypertrophy, with a significant prolongation of the time course of the intracellular calcium transient. This may contribute to abnormalities of left ventricular filling. ${ }^{32,33}$ Finally, left ventricular relaxation may also be altered on the basis of load-dependent effects, decreased myocardial wall stress, and changes in contractile state. Since we did not demonstrate changes in loading conditions as reflected by left ventricular end-diastolic volume, blood pressure, wall stress, or systolic performance, it is unlikely that these loading factors contributed significantly to the alterations in left ventricular filling that we observed. In this regard, our neurogenic model of left ventricular hypertrophy has advantages over other models that induce sustained hypertension, since it is well appreciated that alterations in loading conditions alone will contribute to changes in diastolic filling. ${ }^{9,22-24}$

Changes in sympathetic drive to the heart may also alter left ventricular filling, and this factor may be an important one in our neurogenic model of left ventricular hypertrophy. Sonnenblick et al. ${ }^{34}$ have previously demonstrated that increased sympathetic drive enhances left ventricular relaxation. Since there exists a close relationship between the rate of rapid filling and relaxation, an enhancement of the rate of rapid filling would be expected when sympathetic drive is accelerated. However, despite evidence of increased sympathetic drive in our neurogenic model of left ventricular hypertrophy, as demonstrated by increases in norepinephrine levels, ${ }^{10}$ the rate of left ventricular filling was decreased as hypertrophy developed, demonstrating a complex interaction of these variables. This interpretation further agrees with the clinical observations of Fouad et al., ${ }^{35}$ who found that hypertensive patients with associated hyperkinetic circulation had a normal left ventricular filling rate, as opposed to those with essential hypertension, who did not. Moreover, $\beta$ blockade in hypertensive patients resulted in an additional reduction in the rate of left ventricular filling when blood pressure was unchanged ${ }^{36}$ further suggesting that sympathetic drive may modulate left ventricular diastolic function.

In conclusion, our echo-Doppler findings in a canine model of progressive left ventricular hypertrophy support the findings in the existing clinical literature, which indicate that an abnormality of left ventricular diastolic filling occurs commonly in left ventricular hypertrophy. Moreover, these left ventricular filling abnormalities are evident early in the course of the development of left ventricular hypertrophy. Although there are several contributing mechanisms, our data indicate that increases of myocardial mass correlate with left ventricular diastolic filling changes, suggesting that increasing chamber stiffness with left ventricular hypertrophy is an important mechanism.

\section{REFERENCES}

1. Grossman W, McLaurin LP. Diastolic properties of the left ventricle. Ann Intern Med 1976;84:316-26.

2. Snider AR, Gidding SS, Rocchini AP, et al. Doppler evaluation of left ventricular diastolic filling in children with systemic hypertension. Am J Cardiol 1985;56:921-6.

3. Phillips RA, Coplan NL, Krakoff LR, et al. Doppler echocardiographic analysis of left ventricular filling in treated hypertensive patients. J Am Coll Cardiol 1987;9:317-22.

4. Gardin JM, Drayer JI, Rohan MK, et al. Doppler evaluation of left ventricular filling in mild and severe hypertension. J Am Coll Cardiol 1986;7:185-92.

5. Pearson AC, Labovitz AJ, Mrosek D, Williams GA, Kennedy HL. Assessment of diastolic function in normal and hypertrophied hearts: comparison of Doppler echocardiography and M-mode echocardiography. AM HEART J 1987;113:1417-25.

6. Pearson AC, Gudipati CV, Labovitz AJ. Systolic and diastolic flow abnormalities in elderly patients with hypertensive hypertrophic cardiomyopathy. J Am Coll Cardiol 1988;12:98995.

7. Szlachcic J, Tubau JF, Vollmer C, Massie BM. Effect of diltiazem on left ventricular mass and diastolic filling in mild to moderate hypertension. Am J Cardiol 1989;63:198-201.

8. Inouye KE, Massie BM, Loge D, Simpson P, Tubau JF. Fail- 
ure of antihypertensive therapy with diuretic, beta-blocking and calcium channel blocking drugs to consistently reverse left ventricular filling abnormalities. Am J Cardiol 1984;53: 1583-7.

9. Brutsaert DL, Rademakers FE, Sys SU. Triple control of relaxation: implications in cardiac disease. Circulation 1984; 69:190-6.

10. Julius S, Li Y, Brant D, Krause L, Buda AJ. Neurogenic pressor episodes fail to cause hypertension but do induce cardiac hypertrophy. Hypertension 1989;13:422-9.

11. Weiss RJ, Buda AJ, Pasyk S, O'Neill WW, Keyes JW Jr, Pitt B. Noninvasive quantification of jeopardized myocardial mass using two-dimensional echocardiography and thallium-201 tomography. Am J Cardiol 1983;52:1340-4.

12. Folland ED, Parisi AF, Moynihan PF, Jones DR, Feldman CL, Tow DE. Assessment of left ventricle ejection fraction and volume by real-time two-dimensional echocardiography. Circulation 1979;60:760-6.

13. Reichek N, Wilson J, St. John Sutton M, Plappert TA, Goldberg S, Hirshfeld JW. Noninvasive determination of left ventricular end-systolic stress: validation of the method and initial application. Circulation 1982;65:99-108.

14. Wind BE, Snider AR, Buda AJ, O'Neill WW, Topol EJ, Dilworth LR. Pulsed Doppler assessment of left ventricular diastolic filling in coronary artery disease before and after coronary angioplasty. Am J Cardiol 1987;59:1041-6.

15. Gwathmey JK, Morgan JP. Altered calcium handling in experimental pressure-overload hypertrophy in the ferret. Circ Res 1985;57:836-43.

16. Harrison DG, Barnes DH, Hiratzka LF, Eastham CL, Kerber RE, Marcus L. The effect of cardiac hypertrophy on the coronary collateral circulation. Circulation 1985;71:1135-45.

17. Douglas PM, Berko B, Lesh M, Reichek N. Alterations in diastolic function in response to progressive left ventricular hypertrophy. J Am Coll Cardiol 1989;13:461-7.

18. Savage DD, Drayer JIM, Henry WL, Mathews EC Jr, Ware JH, Gardin JM, Cohen ER, Epstein SE, Laragh JH. Echocardiographic assessment of cardiac anatomy and function in hypertensive subjects. Circulation 1979;59:623-32.

19. Fouad FM, Slominski JM, Tarazi RC. Left ventricular diastolic function in hypertension: relation to left ventricular mass and systolic function. J Am Coll Cardiol 1985;5:869-74.

20. Inouye I, Massie B, Loge D, Hirsch A, Tubau JT. Abnormal left ventricular filling: an early finding in mild to moderate hypertension. Am J Cardiol 1985;56:546-50.

21. Bonow RO, Rosing PR, Backarach SL, Green MV, Kent KM, Lipson LC, Maron BJ, Leaon MB, Epstein SE. Effects of verapamil on left ventricular systolic function and diastolic filling in patients with hypertrophic cardiomyopathy. Circulation $1981 ; 64: 787-96$.
22. Choong CY, Abascal VM, Thomas JD, Guerrero JL, McGlew $\mathrm{S}$, Weyman AE. Combined influence of ventricular loading and relaxation on the transmitral flow velocity profile in dogs measured by Doppler echocardiography. Circulation 1988; $78: 672-83$

23. Ishida Y, Meisner JS, Tsujioka K, Gallo JI, Yoran C, Frater RWM, Yellin EL. Left ventricular filling dynamics: influence of left ventricular relaxation and left atrial pressure. Circulation 1986;74:187-96.

24. Courtois M, Vered Z, Barzilai B, Ricciotti NA, Perez JE, Ludbrook PA. The transmitral pressure-flow velocity relation. Effect of abrupt preload reduction. Circulation 1988;78:1459-68.

25. Gaasch WH, Levine JH, Quinones MA, Alexander JK. Left ventricular compliance: mechanisms and clinical implications. Am J Cardiol 1976;38:645-53.

26. Bing OHL, Matsushita S, Fanburg BL, Levine HJ. Mechanical properties of rat cardiac muscle during experimental hypertrophy. Circ Res 1971;28:233-45.

27. Jalil JE, Doering CW, Jamicki JS, Pick R, Shroff SG, Weber KT. Fibrillar collagen and myocardial stiffness in the intact hypertrophied rat left ventricle. Circ Res 1989;64:1041-50.

28. Gaasch WH. Left ventricular radius to wall thickness ratio. Am J Cardiol 1979;43:1189-94.

29. Smith VE, Schulman P, Karimeddini MK, White WB, Meeran MK, Katz AM. Rapid ventricular filling in left ventricular hypertrophy. II. Pathologic hypertrophy. J Am Coll Cardiol 1985;5:869-74.

30. Gardin JM, Drayer JIM, Weber M, Rohan MK, Knoll M, Shu VWC, Garcia R, Brewer D, Henry WL. Doppler echocardiographic assessment of left ventricular systolic and diastolic function in mild hypertension. Hypertension 1987;9 (suppl II):II-90-96

31. Fouad FM. Left ventricular diastolic function in hypertensive patients. Circulation 1987;75(suppl I):I-48-55.

32. Gwathmey JK, Morgan JPL. Altered calcium handling in experimental pressure-overload hypertrophy in the ferret. Circ Res 1985;57:836-43.

33. Lecarpenter Y, Martin JL, Gastineau P, et al. Load dependence of mammalian heart relaxation during cardiac hypertrophy and heart failure. Am J Physiol 1982;242:H855-61.

34. Sonnenblick EH, Wiegel JH, Sarnofr SJ. Ventricular distensibility and pressure-volume curve during sympathetic stimulation. Am J Physiol 1963;204:1-4.

35. Fouad FM, Tarazi RC, Gallagher JH, MacIntyre WJ, Cook SA. Abnormal left ventricular relaxation in hypertensive patients. Clin Sci 1980;59:411-4.

36. Fouad FM, Slominski MJ, Tarazi RC, Gallagher J. Alterations in left ventricular relaxation and filling with beta adrenergic blockade. Am J Cardiol 1983;51:161-4. 